\title{
İmplant-Çimento Arayüzeyinin Kesme Dayanımını Etkileyen Faktörlerin İncelenmesi
}

\author{
Sait Koçak ${ }^{1}$, Tezcan Şekercioğlu ${ }^{2 *}$
}

\section{ÖZ}

Çimentolu kalça implantı bağlantılarında görülen en önemli hasarlardan biri aseptik gevşemedir. Aseptik gevşemede kemik-çimento ve çimento-implant arayüzeylerinde ayrılmalar meydana gelebilmektedir. Arayüzeylerde ne kadar dayanıklı bağlantılar elde edilebilirse o kadar uzun ömürlü cerrahi operasyonlar gerçekleştirilmiş olur. Çimento-implant arayüzeylerinde baskın olan gerilme, kesme gerilmesidir. Bu çalışmada pin-halka test yönteminden faydalanılarak çimento-implant arayüzeyinin kesme dayanımı araştırılmıştır. Ayrıca implant malzemesinin, yüzey pürüzlülüğünün ve çimento manto kalınlığının değişmesi ile arayüzey kesme dayanımında meydana gelen değişmeler incelenmiştir. İmplant malzemesi olarak implant üretiminde yaygın bir şekilde kullanılan titanyum alaşımı ve paslanmaz çelik malzemeler kullanılmıştır. Yüzey pürüzlülüğü, farklı boyutlarda alüminyumoksit taneleri ile kumlama sonucunda elde edilmiştir. Delrinden imal edilen farklı iç çap ölçülerine sahip burçlar ile farklı manto kalınlıkları elde edilmiştir. Elde edilen bulgular, yüzey pürüzlülüğünün artması ile arayüzey kesme dayanımının arttığını, titanyum alaşımı malzemenin daha yüksek arayüzey bağlantısı sağladığını ve ideal manto kalınlığının 2-3 mm arasında olduğunu göstermektedir.

Anahtar Kelimeler: Kemik çimentosu, implant, kesme dayanımı, pim-halka testi

\section{Investigation of Factors Affecting Shear Strength of Implant- Cement Interface}

\begin{abstract}
One of the most important failure in cemented hip replacement is aseptic loosening. Separation may occur at the bone-cement and cement-implant interfaces because of aseptic loosening. The more durable connections can be obtained at the interfaces; the longer surgical operations are performed. The predominant stress at cement-implant interfaces is shear stress. In this study, the shear strength of the cement-implant interface was investigated by using the pin-collar test method. In addition, changes in interfacial shear strength with changes in implant material, surface roughness and cement mantle thickness were investigated. Titanium alloy and stainless-steel materials widely used in implant manufacturing, were used as implant materials. Surface roughness values were obtained by sandblasting with different sized aluminium oxide grains. Different mantle thicknesses have been achieved with the bushes with variable inner diameter sizes made of Delrin. The results show that with the increase in surface roughness, the interface shear strength increases, the titanium alloy material provides higher interface connection, and the ideal mantle thickness is between 2-3 $\mathrm{mm}$.
\end{abstract}

Keywords: Bone cement, implant, shear strength, pin and collar test

\footnotetext{
" Iletișim Yazarı

Geliş/Received

26.01 .2021

Kabul/Accepted

: 23.02.2021

1 Pamukkale Üniversitesi Teknoloji Fakültesi Mekatronik Mühendisliği Bölümü, Denizli skocak@pau.edu.tr, ORCID: 0000-0002-5597-9274

2 Pamukkale Üniversitesi Teknoloji Fakültesi Mekatronik Mühendisliği Bölümü, Denizli tsekerci@pau.edu.tr, ORCID: 0000-0002-9359-8843
} 


\section{EXTENDED ABSTRACT}

\section{Introduction}

Aseptic loosening, which is common in cemented hip implants, is a problem that bio mechanists have been working on for many years. Finite element and similar analysis on the structure of total hip replacement show that compression, tensile and shear stresses occur at the bone-cement and cement-implant interfaces. It is very important to determine the strength values of bone-cement and cement-implant interfaces to determine the causes of aseptic loosening. Therefore, the strength values of both interfaces in tensile, shear, fatigue and mixed mode loading conditions and the factors affecting these values have been extensively investigated in the literature.

\section{Objectives}

In this study, it was tried to experimentally determine the cement-implant interface shear strength by pin and collar tests. The effects of implant material, surface roughness and mantle thickness on interface shear strength were investigated. The pin and collar test is a widely used mechanical test method to measure the interfacial adhesion force of cylindrical materials. In the pin and collar test, shear force is clearly applied to the adhesion area and the shear strength of the interface is determined correctly. There is a part of cylindrical area in the structure of total hip replacement. When a load is applied to the femoral head, a situation like the shear test occurs in the cylindrical regions. In this regard, EN ISO 10123 standard is widely used to testing anaerobic adhesives. However, there is no standard in this scope for testing bone cement interfaces. For this reason, the experimental study was similar to the experimental configuration of Messick et al.

\section{Methods}

Titanium alloy and stainless steel, which are frequently used in implant manufacturing, were used in the experiments as an implant material. Cemented hip prostheses surface, which will remain in the cement after they leave the machining are sandblasted under pressure using aluminium oxide particles. Sandblasting with different sizes of sands (EKF 16, EKF 24, EKF 46, EKF 60) onto the surface, sample surfaces with different surface roughness values were obtained. In the samples where the effect of surface roughness on shear strength was investigated, the cement mantle thickness was kept constant and taken $3 \mathrm{~mm}$. Three different samples were tested for each parameter. In the experiments investigating the effect of mantle thickness, the implant material (titanium alloy) and surface roughness value (sandblasted surface with EKF 46) were kept constant. The cement-implant interface has been tested for mantle thicknesses of 2, 3, 4 and $5 \mathrm{~mm}$. Three different test specimens were tested for each mantle thickness. Delrin material was used as the bushing (ring) material in the experiments in which the effects of both surface roughness and mantle thickness were investigated. Instron 8801 dynamic tensile-compression device was used. Loading speed $0,5 \mathrm{~mm} / \mathrm{min}$ has been selected.

\section{Results}

When titanium alloy is used as an implant material, the lowest surface roughness value obtained is $R_{a} 2,68$ $\mu \mathrm{m}$ and the average shear strength obtained at this value is $5,99 \mathrm{MPa}$, while the highest surface roughness value is $R_{a} 7,56 \mu \mathrm{m}$ and the average shear strength obtained at this value is 10,46 MPa. The smallest surface roughness value obtained when stainless steel is used as implant material is $R_{a} 2,43 \mu \mathrm{m}$ and the average shear strength obtained at this value is $4,83 \mathrm{MPa}$, while the highest surface roughness value is $\mathrm{R}_{\mathrm{a}} 6,60 \mu \mathrm{m}$ and the average shear strength obtained at this value is $8,73 \mathrm{MPa}$. With the increase in surface roughness, the interface shear strength of both materials has increased. At the same surface roughness values, the titanium alloy material showed higher shear strength than the stainless-steel material. The difference can be attributed to the surface energies of materials. While the shear strength obtained in the smallest mantle thickness $(2 \mathrm{~mm})$ was $7,91 \mathrm{MPa}$, this value was obtained as $3,93 \mathrm{MPa}$ in the largest mantle thickness (5 $\mathrm{mm}$ ). It is thought that additional bending stresses occur in the cement mantle as the thickness of the cement mantle increases and these stresses reduce the shear strength by causing tensile stresses at the interface.

\section{Discussion}

In this experimental study, the implant-cement interfaces were tested, and the interface strength increased significantly as the implant surface roughness increased. Although the implant material did not have a significant effect on shear strength, titanium alloy materials showed slightly higher values at the same surface roughness values. Approximately $50 \%$ decrease in interface strength has been detected with the increase of cement mantle thickness from $2 \mathrm{~mm}$ to $5 \mathrm{~mm}$. It can be said that the mantle thickness should not exceed 2-3 mm. Comparing the pin and collar shear test results with the normal tensile-shear tests given in the literature, approximately $300 \%$ higher shear strengths were obtained in the pin and collar shear tests at the same surface roughness values. For this reason, in cement-implant connections, connection geometries should be tried to be created in a way that shear stress is applied to the connection as much as possible. 


\section{GİRIŞ}

Çimentolu kalça implantlarında görülen aseptik gevşeme biyomekanikçilerin uzun yıllardır üzerinde çalıştıkları bir problemdir. Total kalça replasmanının yapısı üzerine yapılan sonlu elemanlar ve benzeri analizler kemik- çimento ve çimento-implant arayüzeylerinde basma, çekme ve kesme gerilmelerinin oluştuğunu göstermektedir [1, 2]. Aseptik gevşemenin nedenlerini saptayabilmek için kemik-çimento ve çimentoimplant arayüzeylerinin dayanım değerlerinin belirlenmesi çok önemlidir. Dolayısıyla literatürde her iki arayüzeyin çekme, kesme, yorulma ve karışık modda yükleme durumlarında dayanım değerleri ve bu değerlere etki eden faktörler yaygın bir şekilde araştırılmıştır.

Sonlu elemanlar metodu kullanılarak yapılan bir çalışmada, krom-kobalt ve titanyum malzemeden oluşan protezler için çimento-kemik ve çimento-protez arayüzeylerindeki mikro hareket ve gerilmeler araştırılmıştır. $4 \mathrm{~mm}$ manto kalınlığı için çimentoimplant ve çimento-kemik arayüzey sürtünme katsayıları sırasıyla 0,4 ve 1,0 olarak tespit edilmiştir. Diğer bir parametre olarak çimento manto kalınlığ $2-7 \mathrm{~mm}$ arasında değiştirilmiş, her iki implant malzemesinin mekanik davranışını da yaklaşık aynı bulunmuştur. İmplant yüzey sertlik değerlerinin de her iki arayüzeyde oluşan mikro hareketin büyüklüğü ve dağılımında önemli bir fark yaratmadığı gözlemlenmiştir. Protez yüzey pürüzlülük değerlerindeki azalmanın, ara yüzeydeki kayma oranını artırdığı, buna karşılık çimento-kemik arayüzeyinde gerçekleşen bağ ayrılmasını azalttığı tespit edilmiş̧ir [3].

Çekme ve kesme karışımı yükleme şartları altında çimento-kemik ara yüzeyinin mekanik davranışlarını belirlemek için geliştirilen hasar modeli kapsamında, yükleme açıları $11,5^{\circ}, 45^{\circ}$ ve $67,5^{\circ}$ altında testler gerçekleştirilmiş ve hasar öncesi ve sonrası durumlardaki mekanik davranış incelenmiştir. Yükleme açısı arttıkça, hasar dayanımlarında kayda değer artışlar tespit edilmiştir. Elde edilen test verileri eliptik hasar kriteri ile değerlendirilmiş, gerçek ve tahmin edilen dayanım arasında ortalama hata $\% 33$ civarında bulunmuştur [4].

Çimento kullanılarak oluşturulan total kalça artroplastisinde meydana gelen aseptik gevşemenin sebeplerini araştırmak için yapılan çalışmada, in vivo şartları mümkün olduğunca sağlayabilmek için insan kadavra dokusu kullanılmış ve kemik-çimento numuneleri hazırlanmıștır. Yapılan çeki yorulma testlerinde, numunelerin hepsinde sertlik kaybı ve yükün kaldırılması sonrası sürünme hasarı tespit edilmiştir. Oluşan hasarların büyük çoğunluğunun sürünme hasarı şeklinde gerçekleştiği vurgulanmıştır. Arayüzeyin yorulma S-N eğrisi, uygulanan gerilme oranına bağlı olarak başlangıçta verilen gerilmenin bir fonksiyonu olarak elde edilmiştir [5].

Çimento-kemik bağlantılarında kesme yorulma yüklemesinin etkileri üzerine yapılan 
bir çalışmada, taze dondurulmuş kadavra femurları kullanılarak, kemik-çimento arayüzeyi içeren test numuneleri hazırlanmıştır. Çatlak kemik arayüzeylerindeki sürünme davranışını kesme ve çekme yorulması yüklerinde açıklayabilmek için von Mises eşdeğer gerilme/deformasyon kavramı kullanmış ve genel bir hasar modeli geliştirilmiştir. Geliştirilen model kullanılarak her iki yükleme durumundaki hasar oluşum zamanı, eşdeğer sürünme gerinim oranı ile yüksek ilişkili $\left(r^{2}=0,971\right)$, eşdeğer başlangıç gerinimi ile kısmi ilişkili $\left(\mathrm{r}^{2}=0,428\right)$ bulunmuştur [6].

Çimentolu toplam kalça replasmanlarının çimento-kemik arayüzünün mikro mekanik davranışlarını belirlemek için yapılan çalışmada, numuneler üzerinde yarı-statik çekme ve basma testleri yapılmış ve dijital görüntü korelasyon tekniklerinden yararlanılmıştır. Uygulanan yükler altında, meydana gelen yer değiştirme miktarının büyük kısmının kemik ve çimento arasındaki ara temas bölgesinde oluştuğu ve çimento-kemik arayüzey çekme mukavemetinin arayüzey temas alanı ile doğru orantılı olduğu tespit edilmiştir. Kemik-çimento numuneleri kullanılarak kayma yorulma yüklemesinin uygulandığı diğer bir çalışmada, in vitro çalışma şartlarında, arayüzeyin rijitliğindeki değişim ve sürünme hasarı, dijital görüntü korelasyon teknikleri kullanılarak ölçülmüştür. Arayüzeyde meydana gelen sürünme hasarının, başlangıçta hızlı bir artış, devamında kararlı bir artış ve son olarak da hızlı bir artış ile üç aşamada gerçekleştiği tespit edilmiştir. Yüklenme büyüklüğü, yükleme çevrim sayısı ve arayüzeydeki temas alanının bir fonksiyonu olarak bulunmuştur. Hasarlı kemik ve çimento numuneler karşılaştırılmış, çimentoda daha çok mikro çatlak gözlemlenmiş ve hasarın da genel olarak arayüzeyde oluştuğu saptanmıştır [7, 8].

Çekme, kesme ve karışık mod yükleme şartları altında çimento-kemik arayüzeyinin mekanik davranışlarını incelemek için yapılan çalışmada, akrilik kemik çimentosu ve sığır kemiği kullanarak testler gerçekleştirilmiştir. Yükleme açısı ve çimento penetrasyon miktarının, bağlantı arayüzey davranışı üzerine etkileri belirlenmeye çalışılmıştır [9]. Ön ısıtma işleminin, implant-çimento arayüzeyinin kesme dayanımı üzerine etkilerinin araştırıldığ kobalt-krom alaşımı kullanılmıştır. Vakum altında standart koşullarda hazırlanan çimento içerisine farklı sıcaklıklarda ön 1sıtma işlemine tabi tutulmuş metal çubukları batırılmıştır. Deney numunelerine, kesme ve basma yükleri uygulanarak, oluşan hasar bölgeleri mikroskop yardımıyla incelenmiştir. Ön ısıtma sıcaklığı yükseldikçe arayüzey kesme dayanımında azalma tespit edilmiştir. Ön ısıtma işlemi ile çimento içindeki boşlukların artması, dayanımdaki azalmanın nedeni olarak gösterilmiştir [10].

Çimento karıştırma tekniğinin karşılaştırıldığı bir çalışmada, el ve vakum ile karıştırılmış çimentolu birleştirmeler test edilmişstir. Çimento kürleştikten sonra çimento porozitesinin dağılımı, çimento-implant ve çimento-kemik arayüzeylerinin dayanımı incelenmiştir. Arayüzeylerde oluşan doğrusal lineer gözenek fraksiyonları yaklaşık 
olarak aynı derecede bulunmuştur. Çimento-kemik arayüzey mukavemetinin karıştırma tekniği ile çok etkilenmediği, çimento-protez arayüzeyinin mukavemetinde ise elle karıştırma ile daha yüksek değerler elde edilebileceği sonucuna varılmıştır. Vakum ile karıştırmanın porozite miktarını değiştirmediği, sadece dağılımını etkilediği vurgulanmıştır [11].

Yorulma hasarı çatlamasının incelendiği çalışmada, in vitro şartlarda iki adet çimentolu femural protez test edilmiştir. Lubinus SPII ve Charnley protezlerinin kullanıldığ Lubinus SPII protezi için çimento mantosunun proksimal bölgesinde daha çok hasar oluştuğu ve mikro çatlakların protez-çimento arayüzünde başlayıp, femur kortikal kemiği yönünde arttığı tespit edilmiştir. Yorulmaya bağlı olarak çimento mantosunda meydana gelen hasarın, proksimal de arttığ 1 ve protez çubuğunun eksenel konumuna göre değiştiği vurgulanmıştır. Manto kalınlığının 2 mm'den büyük olduğu durumlarda, kalınlığın mekanik davranışı çok etkilemediği ancak kemik-çimento arayüzünde mikro çatlak oluşumunu arttırdığı belirtilmiştir [12]. İmplant-çimento arayüzey mekanik davranışını belirlemek için yapılan diğer bir çalışmada, karışık modda çekme ve kesme yüklemesi altında ve farklı yüzey pürüzlülük değerlerinde deneyler yapılmıştır. Sade çekme ve kesme değerleri için yükleme açısı değiştirilerek yapılan testlerde, yüzey pürüzlülüğü arttıkça arayüzeyin dayanımı artmıştır. Arayüzey dayanımı, saf kesmede daha yüksek bulunurken saf çekmede daha düşük değerler elde edilmişstir [13].

Titanyum-polimetilmetakrilat kemik çimentosu arayüzey kesme dayanımını arttırmak için atmosfer basıncı DBD plazması kullanarak titanyum üzerine metilmetakrilat esaslı kaplama yapılmış çalışmada, plazma aktive edilmiş hem de plazma kaplanmış farklı deney numuneleri çimento içerisine yerleştirilerek çekme testleri (pull-out test) gerçekleştirilmiştir. Yapılan yüzey işlemi ile yapışma kuvvetinde \%50'lere varan artışlar tespit edilmiştir. Sadece plazma uygulanan numuneler, yaşlandırma testleri sonucunda iki hafta içinde orijinal yapışma özelliklerine geri dönerken, plazma kaplı numunelerin ise durumlarını koruduğu görülmüştür [14].

Çimento-kemik arayüzeyinin yorulma davranışının araştırıldığı bir çalışmada, dinamik yükler altında, çimento ile birleştirilmiş numuneler test edilmiş ve deney numuneleri kesme yükü altında $10^{6}$ yük tekrarına kadar yüklenmiştir. Kemik-çimento, çimento-implant arayüzeylerinde oluşan gevşeme miktarları Sayısal Görüntü Korelasyon yöntemi kullanılarak tespit edilmiştir. Kemik-çimento arayüzü boyunca gevşemenin bir sonucu olarak hasarın başladığı, kemik yüzey pürüzlülüğü ve çimento kaynaşma derecesi ile yorulma mukavemetinin artış gösterdiği sonucuna varılmıştır [15].

Kadavradan alınan çimentolu kalça protezinden küçük numuneler hazırlanarak, çekme-basma yükleri altındaki mekanik davranışlarının incelendiği bir çalışmada, çimento-kemik arayüzünün sertlik ve çekme dayanım değerleri, laboratuvarda ha- 
zırlanan numunelere göre çok daha düşük bulunmuştur [16]. Diğer bir çalışmada, laboratuvarda hazırlanan ve ölmüş insandan elde edilen çimento-kemik arayüzleri tahribatsız, çok eksenli yükleme şartları altında test edilmiştir. Numunelere, özel tasarım yükleme disklerine monte ederek, arayüzeye göre $0,30,60$ ve $90^{\circ}$ olacak şekilde yük uygulanmıştır. $0^{\circ}$ çekme gerilmesine karşılık gelirken, $90^{\circ}$ kesme gerilmesini temsil etmektedir. Çekmedeki çimento-kemik arayüz dayanımı, $0^{\circ}$ yükleme açısındaki basma yüküne göre daha yüksek elde edilmiştir [17].

Plastik malzemelerin yüzey enerjileri düşüktür. Bu nedenle, plastik malzemeler üzerine uygulanan plazma, korona gibi yüzey işlemlerinin yapışma mukavemeti üzerine olan etkileri de deneysel olarak araştırılmıştır. Ön hazırlık işlemlerinin uygulanması ve yüzey enerjilerinin arttırılması ile plastik malzemelerin yapışmaya karşı gösterdikleri direncin etkisi azaltılmıştır. Mekanik aşındırma uygulanıp yapıştırılan yüzeylerde de daha yüksek bağlantı mukavemet değerleri elde edilmiştir [18, 19].

Doktora tezi kapsamında, çimento ile birleştirilmiş kalça implantlarının dayanım değerleri hem deneysel hem de sayısal olarak araştırılmıştır. Birleşme arayüzeylerine çekme, kesme ve darbe yükleri uygulanarak, in vitro şartlarda arayüzey dayanımları test edilmiş, elde edilen deneysel veriler sonlu elemanlar programına dayanım değeri olarak girilmiş ve total kalça replasmanının hasar analizi gerçekleştirilmişstir. Çimento-implant arayüzeyinin mekanik dayanımına etki edebileceği düşünülen implant malzemesi, implant yüzey pürüzlülüğü ve manto kalınlığ1 gibi parametreler incelenmiştir [20, 21].

Yapılan bu deneysel çalışma kapsamında, pim-halka testleri ile çimento-implant arayüzey kesme dayanımı belirlenmeye çalışılmıştır. Yüzey pürüzlülüğü, implant malzemesi ve manto kalınlığı gibi parametrelerin arayüzey kesme dayanımına etkileri araştırılmıştır. Pim-halka kesme testi (pin and collar test), silindirik malzemelerin arayüzey yapışma dayanımını ölçmek için kullanılan bir yöntemdir. Pim-halka testinde, yapışma bölgesine net bir şekilde kesme kuvveti uygulanmakta ve arayüzeyin kesme dayanımı belirlenmektedir. Femur başına yük uygulandığı zaman protez üzerinde bulunan silindirik bölgelerde de kesme testine benzer bir durum oluşmaktadır. Ancak, kemik çimentolarının testine ait bu kapsamda bir standart mevcut değildir. Bu konuya en yakın anaerobik yapıştırıcıların test edilmesine ilişkin EN ISO 10123 standardı bulunmaktadır [22]. Bu yüzden, Messick ve arkadaşlarının deneysel konfigürasyonuna benzer şekilde testler gerçekleştirilmiştir.

\section{MATERYAL METOD}

İmplant-çimento arayüzey dayanım değerleri, pim-halka kesme deneyleri ile tespit edilmiştir. Kesme deneylerinde, arayüzey kesme dayanımını etkileyen üç parametre dikkate alınmıştır. Bunlar; implant malzemesi, implant yüzey pürüzlülüğü ve arada 
oluşan çimento manto kalınlığıdır. İmplant malzemesi olarak titanyum alaşımı ve paslanmaz çelik kullanılmıştır. Uygulamada, çimentolu kalça protezlerinin çimentonun içinde kalacak olan kısmı alüminyum oksit parçacıklar kullanılarak basınç altında kumlanmaktadır. Bu nedenle, farklı büyüklüklerdeki kumların yüzeye püskürtülmesi ile farklı yüzey pürüzlülük değerlerine sahip numune yüzeyleri elde edilmiştir [20]. Yüzey pürüzlülügüünün etkisinin araştırıldığ 1 deney numunelerinde çimento manto kalınlığ sabit tutularak 3 mm alınmıştır. Manto kalınlığ,$(\varnothing D-15) / 2$ şeklinde hesaplanan kalınlıktır. Her bir parametre için üç farklı numune test edilmiştir. Şekil 1'de numune boyutları verilmiştir.

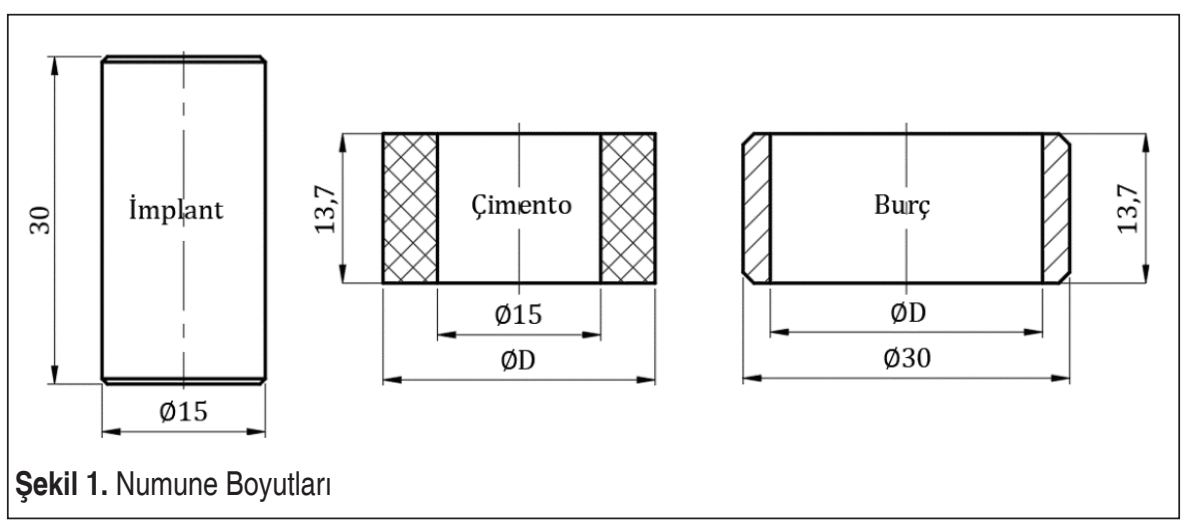

İmplant malzemesi ve yüzey pürüzlülüğü değeri sabit tutularak, manto kalınlığının etkisi araştırılmıştır. İmplant malzemesi olarak EKF 46 ile kumlanmış titanyum alaŞımı numuneler kullanılmıştır. 2, 3, 4 ve $5 \mathrm{~mm}$ manto kalınlıklarının herbiri için

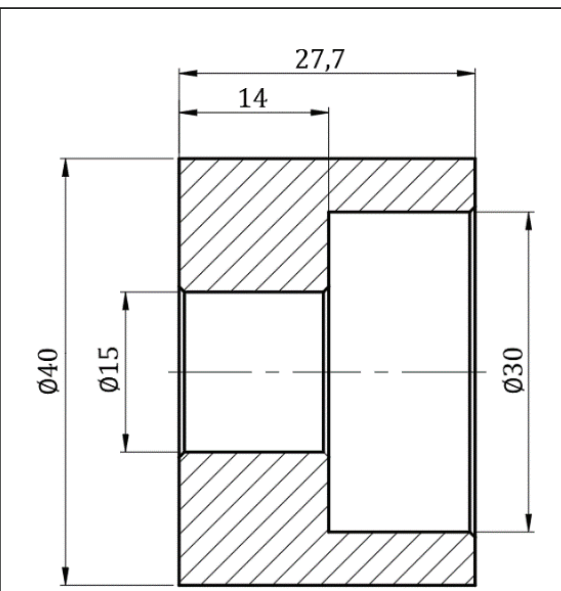

Şekil 2. Silindirik Numuneleri Merkezleme Aparatı üç farklı deney numunesi test edilmiştir. Hem yüzey pürüzlülüğünün hem de manto kalınlığının etkilerinin araştırıldiğ 1 deneylerde burç (halka) malzemesi olarak Delrin kullanılmıştır. Testlerde kullanilan implant numuneleri, kemik çimentosunu çevreleyen silindirik burçlara merkezlemek için Messick ve arkadaşlarının [11] kullanmış oldukları aparata benzer Şekil 2'de verilen aparat kullanılmıştır. İlk olarak silindirik burçlar aparatın içine yerleştirilmiş, daha sonra burçların içine çimento doldurulmuş ve titanyum ve paslanmaz çelik implant numuneler çimentoya bastırıla- 
rak klimatik kabinde literatüre uygun olarak 48 saat kürleşmeye bırakılmıştır.

Teste hazır halde birleştirilmiş farklı manto kalınlıklarındaki kesme deney numuneleri Şekil 3'te ve test cihazına bağlantı koşulları Şekil 4'te verilmiştir.
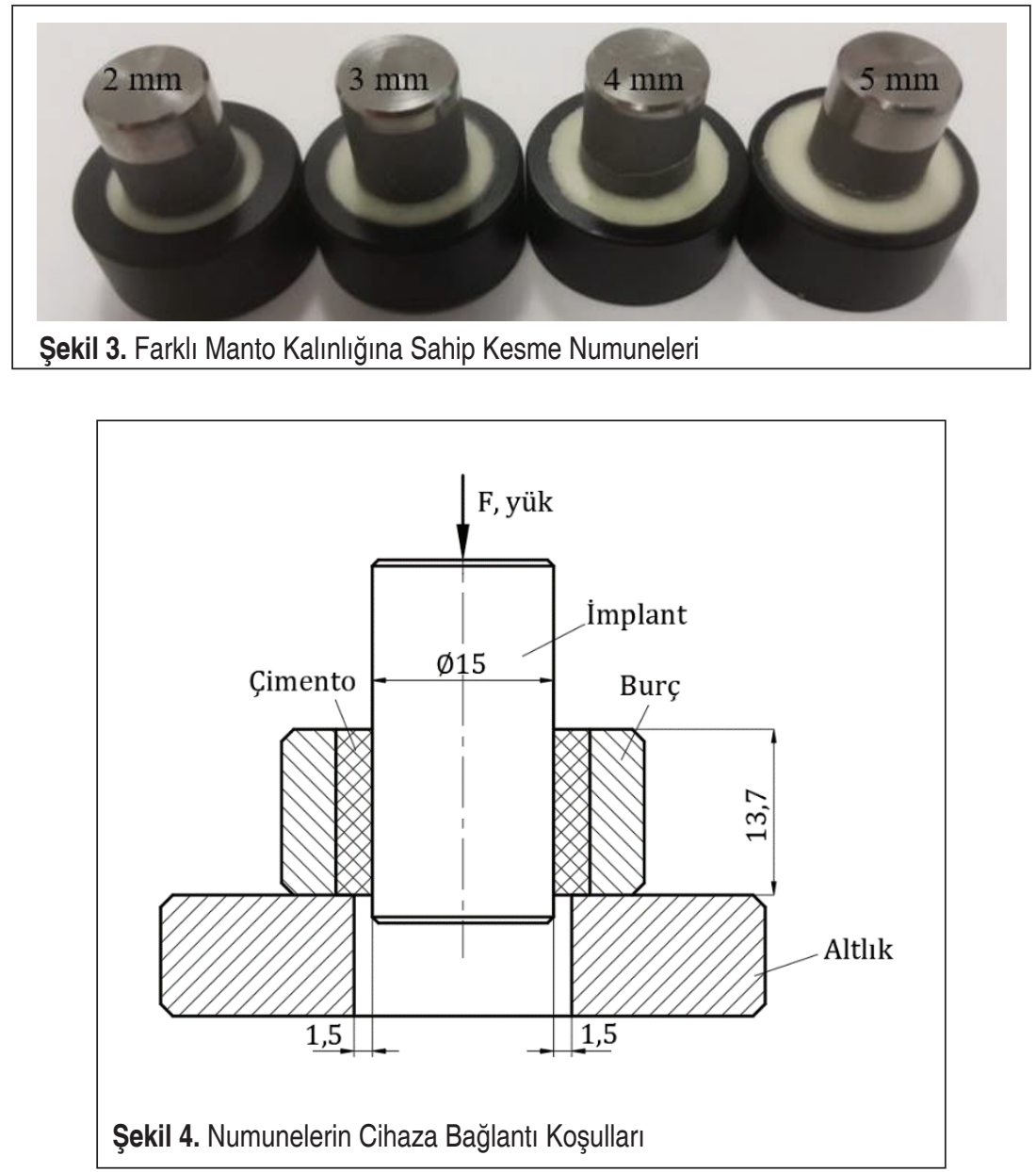

Kürlenmiş numunelere yük uygulama aşamasında, Instron 8801 çekme-basma test cihazı kullanılmıştır (Şekil 5). Testlere başlamadan önce, numunelerin çapları ve yapıştırma boyutları cihaza veri olarak girilmiştir. Literatüre uygun olarak yükleme hızı $0,5 \mathrm{~mm} / \mathrm{min}$ seçilmiştir. Çekme cihazının alt çenesine altlık plaka yerleştirilerek numuneler cihaza bağlanmış ve implantın üst yüzeyinden kuvvet uygulanmıştır. Testler sonucunda cihazdan maksimum yük ve deplasman değerleri alınmıştır. Cihaza bağlanmış deney numunelerinden bir tanesi Şekil 6'da gösterilmektedir. 


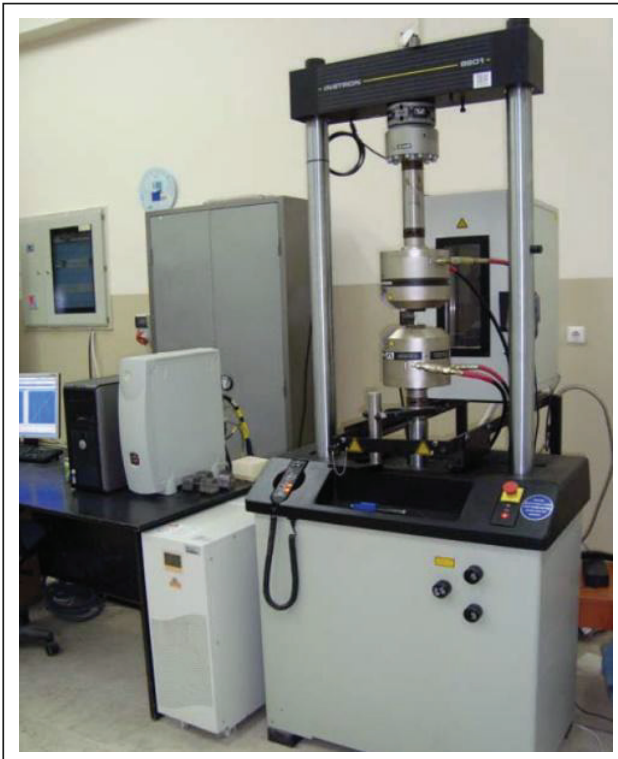

Şekil 5. Deneylerde Kullanılan Instron 8801 Çekme-Basma Test Cihazı

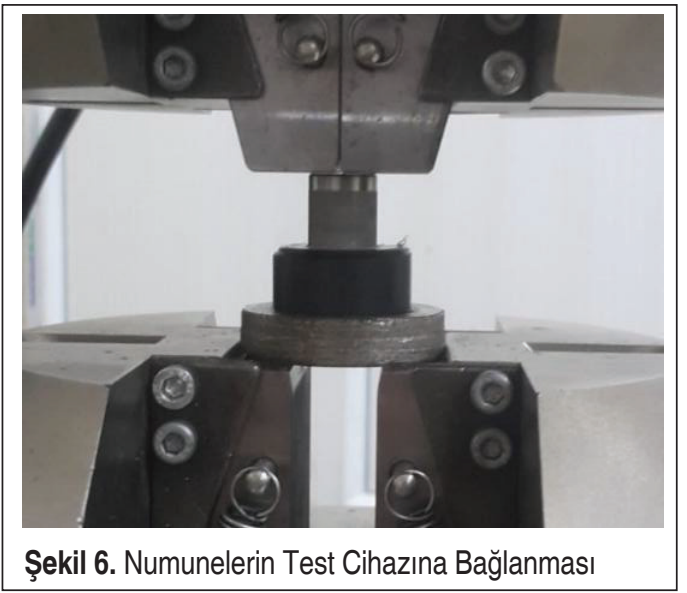

\section{BULGULAR VE TARTIŞMA}

\subsection{Yüzey Pürüzlülüğünün Etkisi}

Titanyum-kemik çimentosu arayüzey kesme deneylerinde dört farklı yüzey pürüzlülüğünde her bir pürüzlülük değeri için üç numune, toplamda 12 numune test edilmiştir. Titanyum-kemik çimentosu arayüzey kesme test sonuçları Tablo 1'de verilmiştir. 
Tablo 1. Yüzey Pürüzlülüğüne Göre Titanyum-Kemik Çimentosu Arayüzey Kesme Dayanımları

\begin{tabular}{|c|c|c|c|c|}
\hline \multirow{2}{*}{$\begin{array}{c}\text { Yüzey Pürüzlülüğü } \\
\left(\mathbf{R}_{\mathrm{a}}, \boldsymbol{\mu m}\right)\end{array}$} & \multicolumn{4}{|c|}{ Kesme Dayanımı, $\tau$ (MPa) } \\
\cline { 2 - 5 } & 1. Numune & 2. Numune & 3. Numune & Ortalama \\
\hline $\mathbf{2 , 6 8}$ & 6,20 & 5,43 & 6,36 & 5,99 \\
\hline $\mathbf{3 , 7 1}$ & 6,98 & 6,74 & 7,36 & 7,03 \\
\hline $\mathbf{6 , 6 3}$ & 8,91 & 8,99 & 9,92 & 9,27 \\
\hline $\mathbf{7 , 5 6}$ & 11,16 & 10,23 & 10,00 & 10,46 \\
\hline
\end{tabular}

Paslanmaz çelik-kemik çimentosu arayüzey kesme deneylerinde dört farklı yüzey pürüzlülüğünde her bir pürüzlülük değeri için üç numune, toplamda 12 numune test edilmiştir. Paslanmaz çelik-kemik çimentosu arayüzey kesme test sonuçları Tablo 2'de verilmiştir.

Tablo 2. Yüzey Pürüzlülüğüne Göre Paslanmaz Çelik-Kemik Çimentosu Arayüzey Kesme Dayanımları

\begin{tabular}{|c|c|c|c|c|}
\hline \multirow{2}{*}{$\begin{array}{c}\text { Yüzey Pürüzlülüğü } \\
\left(\mathbf{R}_{\mathrm{a}}, \boldsymbol{\mu m}\right)\end{array}$} & \multicolumn{4}{|c|}{ Kesme Dayanımı, $\tau$ (MPa) } \\
\cline { 2 - 5 } & 1. Numune & 2. Numune & 3. Numune & Ortalama \\
\hline $\mathbf{2 , 4 3}$ & 4,50 & 4,88 & 5,12 & 4,83 \\
\hline $\mathbf{3 , 4 5}$ & 6,20 & 6,82 & 6,59 & 6,54 \\
\hline $\mathbf{5 , 6 8}$ & 8,45 & 8,53 & 6,98 & 7,98 \\
\hline $\mathbf{6 , 6 0}$ & 8,37 & 9,15 & 8,68 & 8,73 \\
\hline
\end{tabular}

Farklı yüzey pürüzlülük değerlerine göre, paslanmaz çelik ve titanyum alaşımı malzemelerin arayüzey kesme dayanımlarındaki değişim, Şekil 7'de gösterilmiştir.

Her iki implant malzemesinde de yüzey pürüzlülüğünün artmasıyla birlikte arayüzey kesme dayanımında artış gözlemlenmiştir. Titanyum alaşımı implant, aynı yüzey pürüzlülüğü değerlerinde paslanmaz çeliğe göre daha yüksek kesme dayanımı göstermiştir. Aradaki fark, malzemelerin sahip olduğu yüzey enerjilerine bağlanabilir.

\subsection{Manto Kalınlığının Etkisi}

Manto kalınlığının etkisini araştırmak için dört farklı kalınlık değeri için üç numune, toplamda 12 numune test edilmiştir. Farklı manto kalınlığına sahip deney numunelerinin arayüzey kesme sonuçları Tablo 3'te verilmiştir. 


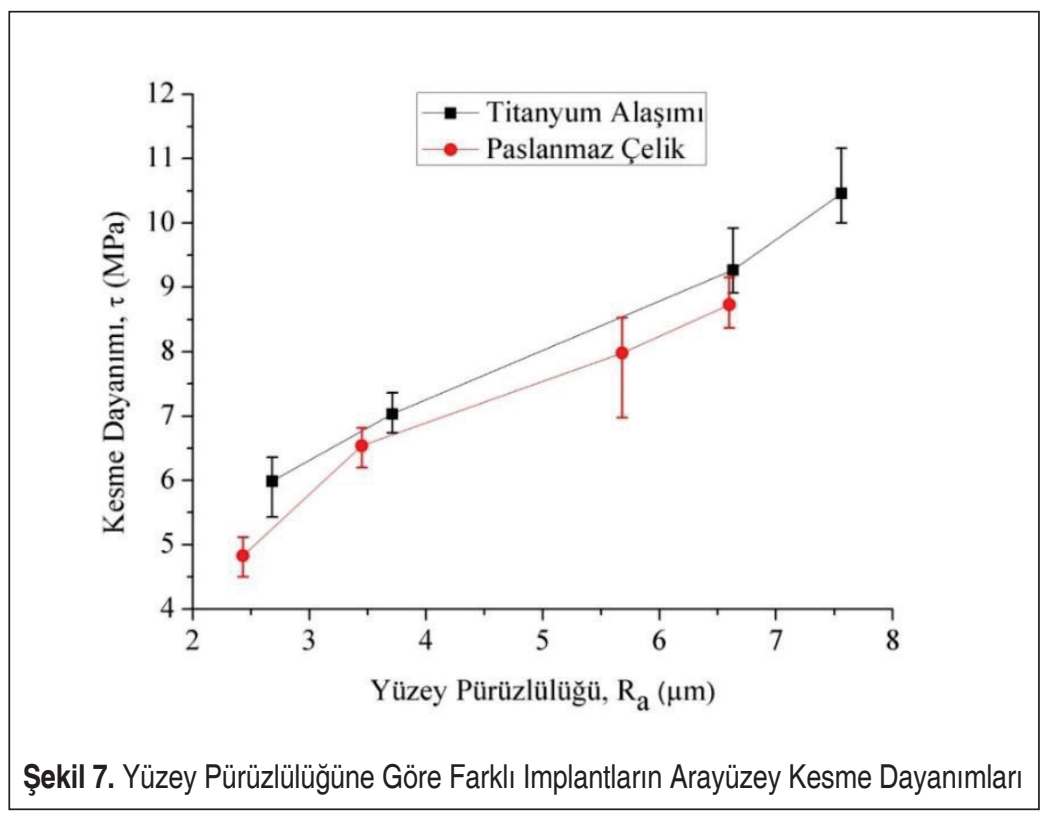

Çimento manto kalınlığının değişmesi ile implant-çimento arayüzey kesme dayanımının değişimi Şekil 8'de verilmiş̧ir.

Manto kalınlığının artmasıyla birlikte arayüzey kesme dayanımlarında ciddi miktarlarda azalma meydana gelmiştir. En düşük kesme dayanımı $5 \mathrm{~mm}$ manto kalınlığında, en yüksek kesme dayanımı ise $2 \mathrm{~mm}$ manto kalınlığında elde edilmiştir. Manto kalınlığının artması ile arayüzeylerde ilave eğilme gerilmelerinin oluştuğu ve bu gerilmelerin arayüzeyde ek çekme gerilmeleri doğurarak kesme dayanımını azalttığı söylenebilir. Ayrıca, manto kalınlığının artması ile kürleşme anında iç yapıdaki düzensizliklerin artmış olabileceği, bu nedenle dayanım değerlerinde azalmalar oluştuğu sonucuna varılmıştır.

Tablo 3. Farklı Manto Kalınlığına Sahip Numunelerin Arayüzey Kesme Dayanımları

\begin{tabular}{|c|c|c|c|c|}
\hline \multirow{2}{*}{$\begin{array}{c}\text { Manto Kalınlığı } \\
(\mathbf{t}, \mathbf{m m})\end{array}$} & \multicolumn{4}{|c|}{ Kesme Dayanımı, $\tau$ (MPa) } \\
\cline { 2 - 5 } & 1. Numune & 2. Numune & 3. Numune & Ortalama \\
\hline $\mathbf{2 , 0 0}$ & 8,14 & 6,67 & 8,91 & 7,91 \\
\hline $\mathbf{3 , 0 0}$ & 7,36 & 6,74 & 6,98 & 7,03 \\
\hline $\mathbf{4 , 0 0}$ & 5,43 & 6,05 & 6,20 & 5,89 \\
\hline $\mathbf{5 , 0 0}$ & 3,10 & 3,26 & 5,43 & 3,93 \\
\hline
\end{tabular}




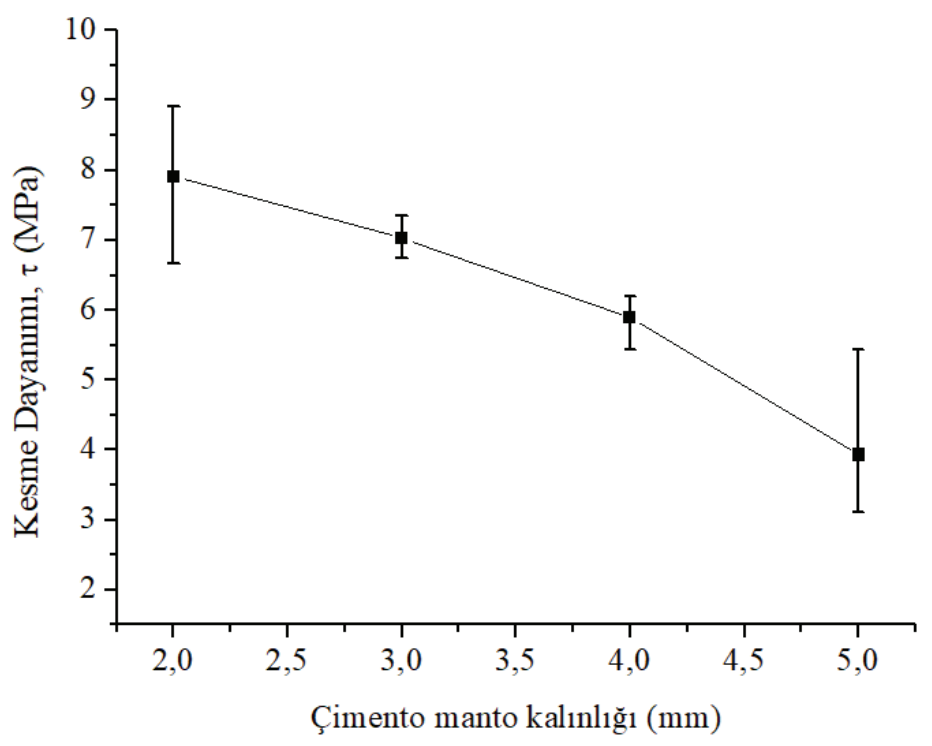

Şekil 8. Çimento Manto Kalınlığının Arayüzey Kesme Dayanımına Etkisi

\section{SONUÇ}

Yapılan deneysel çalışmada, implant-çimento arayüzeyleri test edilerek, kesme dayanımı üzerine yüzey pürüzlülüğünün, implant malzemesinin ve manto kalınlığının etkileri araştırılmıştır. Yüzey pürüzlülüğünün artması ile arayüzey dayanım değerlerinde önemli artışlar tespit edilmiştir. Bağlantı dayanımı üzerine implant malzemesinin önemli bir etkisi tespit edilememiş, titanyum alaşımı numunelerde yaklaşık \%3-6 daha yüksek dayanım değerleri elde edilmiştir. Çimento manto kalınlığının artmasıyla birlikte arayüzey dayanım değerinde yaklaşı $\% 50$ azalma tespit edilmiştir. Test sonuçlarına göre, uygulamada manto kalınlığının 2-3 mm'yi geçmemesi önerilebilir. Kesme deney sonuçları ile literatürde $[13,20]$ verilen normal çekme-kesme deneyleri mukayese edildiğinde aynı yüzey pürüzlülük değerleri için pim-halka kesme deneylerinde yaklaşık \%300'e varan oranlarda daha yüksek kesme dayanımları elde edilmiştir. Bu nedenle, kemik-çimento bağlantılarında, bağlantıya mümkün olduğu kadar kesme gerilmesi gelecek şekilde bağlantı geometrileri oluşturulmaya çalışılmalıdır.

\section{TEŞEKKÜR}

Bu çalışma, Pamukkale Üniversitesi Bilimsel Araştırma Projeleri Birimi (PAUBAP) tarafından, 2017FEBE015 nolu proje kapsamında desteklenmiştir. 


\section{KAYNAKÇA}

1. Bousnane, T., Benbarek, S., Sahli, A., Serier, B., \& Bouiadjra, B. A. B. 2018. "Damage of the bone-cement interface in finite element analyses of cemented orthopaedic implants", Periodica Polytechnica Mechanical Engineering, 62 (2), 173-178. Doi: 10.3311/PPme.11851.

2. Koçak, S., Şekercioğlu, T. 2019 "Experimental and numerical static failure analyses of total hip replacement interfaces", Proceedings of the Institution of Mechanical Engineers, Part H: Journal of Engineering in Medicine, 233 (11), 1183-1195. Doi: $10.1177 / 0954411919877305$.

3. Ramaniraka, N.A., Rakotomanana, L.R., Leyvraz, P.F. 2000. "The fixation of the cemented femoral component: effects of stem stiffness, cement thickness and roughness of the cement-bone surface", The Journal of Bone and Joint Surgery, 82-B (2), 297-303. Doi: 10.1302/0301-620X.82B2.0820297.

4. Mann, K.A., Mocarski, R., Damron, L.A., Allen, M.J., Ayers, D.C. 2001. "Mixed-mode failure response of the cement-bone interface", Journal of Orthopaedic Research, 19 (6), 1153-1161. Doi: 10.1016/S0736-0266(01)00036-5.

5. Kim, D.G., Miller, M.A., Mann, K.A. 2004. "A fatigue damage model for the cement-bone interface”, Journal of Biomechanics, 37 (10), 1505-1512. Doi: 10.1016/j. jbiomech.2004.01.011.

6. Kim, D.G., Miller, M.A., Mann, K.A. 2004. "Creep dominates tensile fatigue damage of the cement-bone interface", Journal of Orthopaedic Research, 22 (3), 633640. Doi: 10.1016/j.orthres.2003.09.007.

7. Mann, K.A., Miller, M.A., Cleary, R.J., Janssen, D., Verdonschot, N. 2008. “Experimental micromechanics of the cement-bone interface", Journal of Orthopaedic Research, 26 (6), 872-879. Doi: 10.1002/jor.20575.

8. Mann, K.A., Miller, M.A., Race, A., Verdonschot, N. 2009. "Shear fatigue micromechanics of the cement-bone interface: an in vitro study using digital image correlation techniques", Journal of orthopaedic research, 27 (3), 340-346. Doi: 10.1002/ jor.20777.

9. Wang, J.Y., Tozzi, G., Chen, J., Contal, F., Lupton, C., Tong, J. 2010. "Bonecement interfacial behaviour under mixed mode loading conditions", Journal of the Mechanical Behavior of Biomedical Materials, 3 (5), 392-398. Doi: 10.1016/j. jmbbm.2010.03.001.

10. Paczocha, P., Indacochea, J.E. 2004. "Effect of Preheating on Implant-Cement Interface Strength for Hip Replacement", Advances in Technology of Materials and Materials Processing, 6 (2), 142-151.

11. Messick, K.J., Miller, M.A., Damron, L.A., Race, A., Clarke, M.T., Mann, K.A. 2007. "Vacuum-mixing cement does not decrease overall porosity in cemented fe- 
moral stems: an in vitro laboratory investigation", The Journal of Bone and Joint Surgery. British volume, 89 (8), 1115-1121. Doi: 10.1302/0301-620X.89B8.19129.

12. Ramos, A., Simões, J.A. 2009. "The influence of cement mantle thickness and stem geometry on fatigue damage in two different cemented hip femoral prostheses", Journal of Biomechanics, 42 (15), 2602-2610. Doi: 10.1016/j.jbiomech.2009.06.037.

13. Zelle, J., Janssen, D., Peeters, S., Brouwer, C., Verdonschot, N. 2011. "Mixedmode failure strength of implant-cement interface specimens with varying surface roughness", Journal of Biomechanics, 44 (4), 780-783. Doi: 10.1016/j.jbiomech.2010.10.037.

14. Cools, P., Geyter, N., Vanderleyden, E., Barberis, F., Dubruel, P., Morent, R. 2016. "Adhesion improvement at the PMMA bone cement-titanium implant interface using methyl methacrylate atmospheric pressure plasma polymerization", Surface and Coatings Technology, 294, 201-209. Doi: 10.1016/j.surfcoat.2016.03.054.

15. Yang, D.T., Zhang, D., Arola, D.D. 2010. "Fatigue of the bone/cement interface and loosening of total joint replacements", International Journal of Fatigue, 32 (10), 1639-1649. Doi: 10.1016/j.ijfatigue.2010.03.005.

16. Miller, M.A., Eberhardt, A.W., Cleary, R.J., Verdonschot, N., Mann, K.A. 2010. "Micromechanics of postmortem-retrieved cement-bone interfaces", Journal of Orthopaedic Research, 28 (2), 170-177. Doi: 10.1002/jor.20893.

17. Miller, M.A., Race, A., Waanders, D., Cleary, R., Janssen, D., Verdonschot, N., Mann, K.A. 2011. "Multi-axial loading micromechanics of the cement-bone interface in postmortem retrievals and lab-prepared specimens", Journal of the Mechanical Behavior of Biomedical Materials, 4 (3), 366-374. Doi: 10.1016/j. jmbbm.2010.11.004.

18. Şekercioğlu, T., Kaner, S. 2014. "Plastiklerin Yapıştırılmasında Yüzey Hazırlama Yöntemlerinin İncelenmesi”, Mühendis ve Makina, 648, 37-43.

19. Kaner, S., Şekercioğlu, T. 2017. "Effect of Surface Pre-treatments and Ageing on the Adhesive Strength of Polymer Joints", Polymer (Korea), 41 (5), 827-834. Doi:10.7317/pk.2017.41.5.827.

20. Koçak, S. 2019. Protezlerde Kullanılan Kemik-Çimento Bağlantılarının Mekanik Özelliklerinin İncelenmesi, Doktora Tezi, Pamukkale Üniversitesi Fen Bilimleri Enstitüsü, Denizli.

21. Koçak, S., Şekercioğlu, T. 2020. "Impact strength of cemented implant interfaces", Materials Testing, 62 (3), 271-276. Doi: 10.3139/120.111481.

22. BS EN ISO 10123. 2019. Adhesives-Determination of shear strength of anaerobic adhesives using pin and collar specimens. 